544 Verh.d. Uebermangans.z. versch. Stoflen etc. - Kryst. v. Calciumoxalat.

\title{
Verhalten der Uebermangansäure zu verschiedenen Stoffen, insbesondere zu aetherischen oelen und Steinkohlenleuchtgas.
}

Mengt man in einem Porzellanschälchen 2 Gewichtstheile vollkommen staublrocknes feingepulvertes übermangansaures Kali mit ohngefähr 2-3 Gewichtstheilen concentrirter Schwefelsäurc, so erhält man nach Prof. K. Böttger ein Gemisch, welches in Folge momentaner Entstehung und Zerlegung von Uebermangansäure in steter Zersetzung begriffen ist. Das Mangansuperoxydhydrat ist das allerenergischste Oxydationsmittel, und zwar in einem weit höheren Grade, als ein Gemisch von Kaliumbichromat und Schwefelsäure. Schon beim blossen Contact dieses Gemisches mit einer grossen Anzahl von Stoffen, insbesondere mit ätherischen Oelen, sieht man, bei gewöhnlicher mittlerer Temperatur, nicht selten die heftigsten Explosionen meist unter Litflammung der betreffenden Körper, eintreten.

Folgende Oele verursachen bei ihrer Berührung mit gonanntem Gemisch Explosionen: Thymianöl, Muskatblüthöl, rectificirtes Terpenthinöl, Spiköl, Zimmtcassiaöl, Dostenöl, Rautenöl, Cubcbenöl, Citronenöl. Mit folgenden Oelen erfolgt meist nur, besonders wenn sie auf Fliesspapier getröpfelt und dann mit dem Gemisch beruhrt werden, eine Entzündung ohne Explosion: Rosmarinöl, Lavendelöl, Gewürznelkenöl, Rosenöl, Geraniumöl, Gaultheriaöl, Kümmelöl, Cajeputöl, ätherisches Bittermandelöl, rectificirtes Steinöl.

Alkohol, Aether, Holzgeist, Benzol, Chlorelayl, Schwefelkohlenstoff entzünden sich blitzschnell und ohne Explosion. 'Trockenes Fliesspapier fängt an zu glimmen unter Ausstossung von rothen Dämpfon; Baumwolle entzündet sich, Schiesswolle dagegen und Schiesspulver nicht. - Reibt 'man staubtrockenes äbermangansaurcs Kali mit trockener Gallussäure zusammen, so erfolgt eine Entzündung unter Funkensprühen; mit Tannin erfolgt bei gleicher Behandlung cine Entziindung meist mit Flanme. - Selbst Steinkohlengas ist gelungen mit dem genannten Gemisch zu entzünden. (Poggendorf's Annalen. Buchner's Repertor. f. Pharmac. Bd. XXII. p. 177.). C. Sch.

\section{Krystalle von Calciumoxalat.}

Vesque hat gelungene Versuche gemacht, auf künstlichem Wege die eigenthümlichen und rerschiedenen Krystalle 
von oxalsaurem Calcium, deren Formen oft fuir bestimmte Gruppen von Pflanzen, in deren Zellen sie sich finden, ebenso constant als charakteristisch sind, dadurch herzustellen, dass er die Bildung der Verbindung unter Bedingungen vor sich gehen liess, von welchen man annehmen darf, dass sie in mehr oder minder ähnlicher Weise auch in der pflanzlichen Zelle vorhanden sind.

Er liess zu diesem Zweck in cin flüssiges Mediun, welches ans Wasser bestand, dem bald Oxalsäure oder Gerbsäure, bald Dextrin, Glucose oder verschiedene Mischungen einzelner oder aller dieser Stoffe zugesetzt waren, einerseits Oxalsäure oder Kaliumoxalat, andererseits Chlorcalcium oder schwefelsaures Calcium in gelöstem Zustande dadurch eintreten, dass er zwei Streifen Fliesspapier mit dem einen Ende in das be. stimmte Medium, mit dem anderen in die betreffenden Lösungen eintauchen liess. Eine Abänderung dieses Verfahrens bestand darin, dass einer der beiden zur Reaction bestimmten Stoffe sich schon mit dem Medium in Mischung befand und nur die Lösung des anderen durch Fliesspapier allmählig eintrat, oder endlich es wurden die Lösungen beider Korper in zwei kleine Dialysatoren gebracht, welche mit ihrem unteren Theile in das Medium eintauchten.

Für jeden einzelnen Nodus giebt es nun als Resultat, welches sich mit Sicherheit wieder hervorrufen lässt, eine ganz bestimmte und constante Form der entstehenden Kry, ställchen von Calciumoxalat. Es sind darunter viele mit den in Pflanzen beobachteten, identische Formen, während andere, wie z. B. dendritische Gestalten bis jetzt in den Zellen noch nicht beobachtet worden sind. Vierstrablige Sterne, rhomboëderartig rhomboïdische Formen und platte Oktä̈der treten bei der künstlichen Herstellung am häufigsten auf. (Journ. de Pharm, et de Chim. 4. Serie, Tome XIX. 211.).

Dr. $G . V$.

\section{Nachweis von Solanin und Solanidin.}

Salmi giebt an, dass Solanin in saurer Lösupng und bei einer Temperatur von mehr als 10 bis $11^{\circ} \mathrm{C}$. in 24 Stunden theilweise in Solanidin und andre Producte zersetzt werde. Diese Zersetzung tritt wohl auch in den Eingeweiden ein, und obgleich die Reactionen auf Solanin bekannt sind, ist dies doch mit Solanidin nicht der Fall. Salmi giebt als Haptreactionen für Solanin an:

Arch. d. Pharm. U. Bda. 6. Bft. 